\title{
Meriting a Response: The Paradox of Seductive Artworks ${ }^{1}$ Nils-Hennes Stear
}

\section{Prescription}

Artworks use artistic methods to elicit responses. Following others, I will say they prescribe responses. What does 'prescribe' mean? One influential sense is Kendall Walton's: a work prescribes a proposition $p$ just in case appreciators ought to imagine $p$ [1990: 39]. Das Boot's final scene, for instance, prescribes that the U96's crew is strafed into oblivion following harrowing months at sea [Petersen 1981]. But in another sense, the scene also prescribes pity. This sense is Berys Gaut's, on which artworks not only prescribe propositions to imagine, but feelings to feel [1998; 2007].

As Aristotle notes, these prescriptions are sometimes unsuccessful:

A perfect tragedy should ... imitate actions which excite pity and fear ... It follows plainly, in the first place, that the change of fortune presented must not be the spectacle of a virtuous man brought from prosperity to adversity: for this moves neither pity nor fear; it merely shocks us. Nor, again, that of a bad man passing from adversity to prosperity: for nothing can be more alien to the spirit of Tragedy; ... it neither satisfies the moral sense nor calls for pity or fear. Nor, again, should the downfall of the utter villain be exhibited. A plot of this kind would doubtless satisfy the moral sense, but it would inspire neither pity nor fear; for pity is aroused by unmerited misfortune, fear by the misfortune of a man like ourselves. ${ }^{2}$

[1898: 45]

1 Special thanks to Ken Walton, Lee Walters, Rohan Sud, Janum Sethi, Chip Sebens, Diego Reynoso, Peter Railton, Thi Nguyen, Alex Neill, Jeremy Lent, Meena Krishnamurthy, Zoë Johnson King, Dan Jacobson, Andrew Huddlestone, Rob Hopkins, Alex Geddes, Berys Gaut, Susan Feagin, Victor Dura-Vila, Daniel Drucker, Gregg Crane, Adriana Clavel-Vázquez, Dan Cavedon-Taylor, Victor Caston, Sarah Buss, Paul Boswell, Paloma Atencia Linares, numerous referees, and the editorial team at AJP. Thanks also to audiences at the Universities of Michigan, Kent, Murcia, and Southampton, Columbia University, UNAM's Seminario de Filosofía de la Mente and the annual meetings of the British Society of Aesthetics (2015) and American Society for Aesthetics (2015). This project was made possible by a postdoctoral grant from the Instituto de Investigaciones Filosóficas, UNAM. It has also received funding from the European Union's Horizon 2020 research and innovation programme under the Marie Skłodowska-Curie grant agreement No 750848. All views are the author's and not necessarily those of the EU.

2 'Perfect' here means 'best' rather than 'paradigmatic'. Aristotle uses ' $x \alpha \lambda \lambda i \sigma \tau \eta \varsigma^{\prime}-$ 'finest', 'most admirable', or sometimes 'beautiful'. See also [Curran 2016: 109]. For criticism of how Aristotle's theory disregards oppressed tragic figures, see [Freeland 1992] and [Curran 1998]. 
A miscast protagonist's downfall will fail to elicit pity and fear.

Unsuccessful prescriptions reveal another difference between Gaut and Walton. Walton's 'prescribe' is a success term; prescribing $p$ makes it normative to imagine $p .{ }^{3}$ Gaut's, however, denotes something artworks attempt to do. For Walton, a work trying to portray James Bond as suave, but inadvertently portraying him as a tool, prescribes that he is a tool; for Gaut it prescribes that he is suave. ${ }^{4}$

Since my discussion concerns prescriptions of diverse response-types that can fail, I use Gaut's concept. Gaut never defines prescription beyond giving examples. ${ }^{5}$ Still, using these, one can say a work prescribes a response just in case, by virtue of all facts relevant to its complete interpretation, it attempts to elicit that response.

\section{The Merit Principle}

From the above quotation, one might anachronistically attribute the following to Aristotle:

\section{ELICITATION PRINCIPLE (EP)}

A work that prescribes but fails to elicit a response in appreciators through artistic means is to that extent aesthetically flawed.

An objection: appreciators might be blameworthy, not the work; they might be irritable, dense, or as Aristotle charges, 'weak' [1898: 47]. Rephrasing in normative rather than causal terms avoids the objection:

\section{MERIT PRINCIPLE (MP)}

A work that prescribes an unmerited response ${ }^{6}$ through artistic means is to that extent aesthetically flawed.

What does '(un)merited' mean? First, meriting and eliciting a response are independent; neither entails the other. This independence is what undermines EP, which collapses the normative (merited) and the causal (elicited). Second, meriting and prescribing a response are independent, as the James Bond example above shows. Third, considerations bearing on meritedness must be all and only those relevant to the work's aesthetic value. Minimally, this excludes 'state-given', as opposed to 'object-given',

3 Conditional on fully appreciating the proposition-prescribing work. (See [Stear 2015: 7]).

4 Gaut thinks his notion is Walton's [Gaut 2007: 230n]. An insight this discussion provides is that they differ significantly. Failure to distinguish them can lead to errors, such as conflating prescribing with meriting a response-see, e.g., [Taylor 2016: 96].

5 See [Gaut 1998: 193, 2007: 229-31].

6 Artworks prescribing unmerited responses do not ordinarily do so under that description, although seductive artworks (discussed below) arguably do. 
reasons $;^{7}$ a kidnapper demanding laughter at gunpoint makes laughter merited in one sense, just not MP's. Separating aesthetically relevant from irrelevant considerations is tricky. Luckily, I do not need to. As I show in \$4.1, provided some considerations count, the problem I identify surfaces (though I must proceed as if certain considerations count to give examples).

MP is well-motivated. First, it captures a general way artworks can fall flat aesthetically. As Richard Moran puts it,

So many familiar terms of aesthetic criticism (for example, the sentimental, the pretentious, etc.) can be seen as expressing judgments of ... the distance between what we are enjoined to feel and what we are inclined to feel.

[1994: 95-6]

Second, it is endorsed by numerous contemporary scholars. ${ }^{8}$ Third, a very different thinker to Aristotle, Hume, appears sympathetic:

An action, represented in tragedy, may be too bloody and atrocious. It may excite such movements of horror as will not soften into pleasure; . . . Such is that action represented in the *Ambitious Stepmother*, where a venerable old man, raised to the height of fury and despair, rushes against a pillar, and striking his head upon it, besmears it all over with mingled brains and gore.

[1757a: 198-9 $]^{9}$

Finally, MP is vital to the best argument for 'ethicism', ${ }^{10}$ the most carefully developed theory of how artworks' moral features impact their aesthetic ones.

Nevertheless, I show how pairing MP with a kind of work I call 'seductive' generates a novel paradox. ${ }^{11}$ I consider some ultimately unsuccessful ways to solve the paradox in $₫ 4$ and $\$ 5$, before concluding that we should abandon MP. I end by considering what makes seductive works theoretically challenging and briefly motivating a promising alternative to MP.

7 See [Jacobson 1997: 170-9] and [Parfit 2011: 27, 50-51, 420-32].

8 Beyond Moran, Gaut [1998, 2007] is MP's foremost advocate. Noël Carroll also appears to support it in [1996: 233, 2000: 377-80]. Robert Stecker [2005] and Andrea Sauchelli [2013] embrace differently qualified MPs susceptible to the paradox I describe.

9 Hume discusses another case where we are unable to 'bear an affection' as directed to characters we deem 'blameable' [1757a: 236-7]

10 Indeed, MP's formulation here is borrowed from [Gaut, 2007, Chapter 10].

11 Such works are first discussed in [Gaut 1998: 192-3] and later in [Gaut 2007: 130n, 185n, 191-202, 230, 2010: 269n]. 


\section{Merit and 'seduction': a paradox}

Ben is an overt misogynist, racist, and murderer; he breaks into houses, injuring, robbing, and killing the inhabitants; a film crew records his crimes and matter-of-fact commentary. Ben is the protagonist of Man Bites Dog [Belvaux, Bonzel, and Poelvoorde 1992], a black comedy 'mockumentary' whose comic premise lies in applying a style often reserved for documenting ordinary jobs to a (fictional) charismatic psychopath. In time, the fictional crew becomes increasingly involved in Ben's crimes before finally joining Ben in committing sexual assault-a metaphor for the appreciators' own complicity. The film is a seductive artwork. Such works constitutively prescribe a response $r_{1}$ to depicted events or features, before prescribing a second-order response $r_{2}$ that repudiates $r_{1}$. Man Bites Dog, for instance, prescribes amusement at Ben's violence until the sexual assault kills any fun, prescribing appreciators to feel ashamed of that amusement.

Seductive works enable a reductio against MP because it entails, implausibly, that such works are necessarily aesthetically flawed: seductive works must prescribe a first-order response and a second-order response repudiating it; in order for the second-order response to be merited, the first-order response it repudiates must be unmerited. Therefore, seductive works must prescribe an unmerited response, making them necessarily aesthetically flawed on MP. This seems counter-intuitive; it is one thing to claim all seductive works happen to be flawed, another that they must be.

Since MP is otherwise compelling, this generates a paradox-three independently plausible but jointly inconsistent claims:

(1) (MP) A work that prescribes an unmerited response through artistic means is to that extent aesthetically flawed.

(2) Seductive works necessarily prescribe an unmerited response through artistic means.

(3) Seductive works are not necessarily aesthetically flawed.

Consistency requires rejecting (1), (2), or (3). Because MP represents the threatened tradition, I devote the next two sections to evaluating the other claims. Moreover, since my account of seductive works represents the puzzle-inducing innovation, I chiefly discuss (2). Finally, I note that while solving the paradox is important, my interest is broader. Few mentions, let alone discussions, of seductive works exist, ${ }^{12}$ even if there

12 Besides Gaut, Matthew Kieran discusses seductive works, including Man Bites Dog in [2006: 138-40]. [Smuts 2007] analyses a film in similar terms. James Harold discusses works inviting 'rich' responses with obvious relevance to what I call 'diachronic' seductive works in [2008: 59]. Mere mentions of seductive works appear in 
are discussions of comparably complex works (e.g., [Eaton 2012]). And though I reject it, what follows represents less an attempt to demolish than to understand MP.

\section{Rejecting (2)}

Rejecting (2) means claiming that artistically seductive works need not prescribe an unmerited response. I offer six intuitive proposals to reject (2). The first three claim successful seductive works' first-order responses can be merited. The last three deny that seductive works must prescribe a first-order response. Within these categories, I have ordered them by increasing plausibility.

\subsection{Autonomist proposal}

Most simply, one could deny that ethical considerations are relevant to meritedness, embracing what some call 'autonomism'. ${ }^{13}$ Being amused by Man Bites Dog, on this proposal, is merited in all aesthetically relevant respects, albeit ethically criticizable.

This approach suffers two problems. First, it only postpones the difficulty, since seductive works can exploit non-ethical considerations. Some Shaggy Dog stories are what one might call 'epistemically seductive works'. Listeners assume the storyteller narrates sincerely, until realizing the plot leads nowhere and they are the butt of a prank. Pliny's Natural History furnishes another example:

[Parrhasius], it is said, entered into a pictorial contest with Zeuxis, who represented some grapes, painted so naturally that the birds flew towards the spot where the picture was exhibited. Parrhasius, on the other hand, exhibited a curtain, drawn with such singular truthfulness, that Zeuxis, elated with the judgment which had passed upon his work by the birds, haughtily demanded that the curtain should be drawn aside to let the picture be seen. Upon finding his mistake, with a great degree of ingenuous candour he admitted that he had been surpassed, for that whereas he himself had only deceived the birds, Parrhasius had deceived him, an artist.

[Pliny 1857: 251]

(Some) Shaggy Dog stories prescribe first-order curiosity and secondorder embarrassment. Parrhasius' painting might prescribe a false firstorder belief about a curtain and a second-order realization that this belief was rash.

[Jacobson 2008], John 2009: 187], [Smuts 2011: 139], and [Thomson-Jones 2012: 282, 284].

13 For a recent survey of autonomist positions, see [Clavel-Vázquez forthcoming]. 
One could save the proposal by also banishing epistemic considerations. However, since seductive works can exploit many kinds of consideration-not just ethical and epistemic, but conventional, prudential, not to mention aesthetic - this helps only if one banishes every kind of consideration. This is doubly hopeless. First, ruling aesthetic considerations irrelevant to an aesthetic form of warrant is ludicrous. Moreover, there clearly are aesthetically seductive works. One example is a 1990's Boddington's Ale advertisement. The short film exquisitely imitates the ultra-aestheticized style of the era's Calvin Klein advertisements until a stern-faced Adonis turns in slow motion towards the camera, operatic music swirling, with a fish on his head [Bartle Bogle Hegarty 1996]. The film prescribes first-order awe at the decadent, monochrome 'beauty', only to reveal that awe's absurdity by exposing the style as pretentious and, indeed, comic. Second, purging every kind of consideration would leave none to determine meritedness at all, meaning the merited/unmerited distinction would track no difference. This would not save MP; it would make it pointless.

The autonomist proposal's second problem is worse. Preserving firstorder meritedness by purging ethical considerations merely relocates the difficulty. For, one rescues the first-order response only by deserting its second-order partner. Consider Man Bites Dog again. If the first-order amusement is merited after all, the second-order shame about that amusement no longer is. Thus, were the amusement merited after all, the work would still prescribe an unmerited response, only a second-order one. The autonomist's path away from (2) leads right back to it.

\subsection{All-things-considered proposal}

Perhaps seductive works need only prescribe a response that is flawed in some respect yet merited all-things-considered, much as donating $\$ 40$ might be less good than donating $\$ 50$, yet permissible. A seductive work could then prescribe a flawed-yet-merited first-order response and a merited second-order response. This second-order response would just be to the first-order response's criticizable portion, and so also merited, keeping the seductive structure without paradox.

The proposal's plausibility, however, presupposes a crude understanding of meritedness. True, responses can be merited all-thingsconsidered (by exceeding some satisfactory threshold) yet regrettable (by not exceeding it enough). But understanding meritedness in subtler pro tanto terms such that, for instance, a response is unmerited in so far as it is unethical, the problem reappears. This is because a work is aesthetically worse, if at all, not (merely) for prescribing all-things-considered unmerited responses, but in so far as a response it prescribes is unmerited. Many responses, and the extent to which they are merited, come in degrees. Imperfect timing, for instance, may make jokes less funny, and thereby aesthetically worse, without making them totally unamusing. MP 
should be read in this pro tanto way, since otherwise these cases get missed, and any interpretation of MP ought to approximate its motivating ambition. Moreover, the all-things-considered reading of MP is weaker than, and would be grounded in, the pro tanto one. So choosing the former to avoid paradox is not a solution; its truth would be explained by the truth of the latter, ${ }^{14}$ which is the principle I will consider from hereon.

\subsection{Shifting standards proposal}

Seductive works seem, paradoxically, to make the unmerited merited, making it in some sense appropriate to respond in a way that is in some sense inappropriate. One way to explain this is by recognizing that different standards of meritedness apply to different kinds of work. One possibility is that seductive works execute a normative shift-for example, by altering operative genre conventions mid-work-thereby changing the standard of meritedness that applies to the seductive work's different parts. Man Bites Dog, for example, might switch from black comedy to realist drama, changing when laughter is appropriate.

This proposal offers a way to preserve MP while explaining how seductive works make the 'unmerited merited'. They shift from one set of genre conventions to another, realizing two different standards of meritedness $\left(s_{1}\right.$ and $\left.s_{2}\right)$; seductive works prescribe a first-order response $\left(r_{1}\right)$ which is merited on $s_{1}$, before prescribing a second-order response $\left(r_{2}\right)$, thereby switching to $s_{2} ; r_{2}$, a response to $r_{1}$, is merited on $s_{2}$ provided $r_{1}$ is unmerited; that $r_{1}$ is unmerited on $s_{2}$ secures this provision. To illustrate, Man Bites Dog prescribes amusement merited by the black comedy standard operative at the time. The film then prescribes shame about that amusement, thereby switching to a realist drama standard. This shame is only merited provided the amusement is not. The amusement's being unmerited on the realist drama standard secures this provision. Therefore, each response a seductive work prescribes can be merited, avoiding paradox and preserving MP (understood with a temporal inflection). ${ }^{15}$

The prescriptions' temporal separation is crucial to the proposal. However, nothing rules out seductive works making their prescriptions simultaneously. In television series Black Mirror's first episode, for example, an anonymous kidnapper threatens to kill a Princess unless the

14 Note also that only the pro tanto version will do for Gaut's influential Merited Response Argument.

15 Is it not a problem that $r 1$ is unmerited by the standard of $s 2$ while $s 2$ is operativethat the amusement in Man Bites Dog, for example, is unmerited by the realist drama standard? Not necessarily, for one could argue that unmerited response are those unmerited according only to standards operative when prescribed. Such a reading would not be ad hoc. The motivation behind Aristotle's and Hume's claims is that lack of meritedness undermines one's ability to respond to a work on its terms. But the fact that a response is unmerited by a standard not even operative when the response is prescribed does not interfere with this ability. 
Prime Minister has intercourse with a pig on live television. As the deadline nears, the unthinkable demand becomes thinkable before finally, compelled by polls and PR aides, the Prime Minister yields [Brooker 2011]. The episode explores how technology turns someone's humiliation into consumer titillation; news spreads quickly via social media, and the humiliating act is broadcast to a gripped public. Yet, crucially the show depicts many viewers realizing the horror of their voyeurism. The series presents a dark reflection (as from a smartphone or flat-screen TV) of our hyper-technological world. The first episode does this through seduction. As one watches the fictional citizens stare at their televisions with unsavoury relish, one realizes one is doing likewise. The work simultaneously prescribes a desire to see the sordid act and a recognition of this desire's perversity. Call it a 'synchronic' seductive work.

Such works scupper the shifting standards proposal ${ }^{16}$ by eliminating the temporal separation it needs. Both standards of meritedness $\left(s_{1}\right.$ and $s_{2}$ ) operate simultaneously. So both prescribed responses $\left(r_{1}\right.$ and $\left.r_{2}\right)$ remain unmerited on one standard $\left(r_{1}\right.$ on $s_{2}$ and $r_{2}$ on $\left.s_{1}\right) .{ }^{17}$ Thus, such works remain necessarily aesthetically flawed even on a temporally inflected reading of MP.

Why think responses to a seductive work can be insulated from a standard only if they are temporally separated? After all, some nonseductive works successfully match responses to one standard and not another, even when they operate simultaneously: Picasso's Guernica prescribes both horror at the depicted war scene and pleasure in the bold use of geometric forms [1937]. What distinguishes seductive works from non-seductive works such as Guernica, however, is that appreciators of synchronic seductive works must get how the first-order response is unmerited to properly appreciate the work's seductive point; the meritedness of one response (second-order) cannot be cleaved from the (un)meritedness of the other (first-order). So even if one assigned each response its own standard, the second-order response cannot be understood without grasping how the first-order response falls short of the second-order response's assigned standard. For the shifting standards proposal to work therefore, MP would need to say that works prescribing a response unmerited according to all standards operative at the time of prescription are to that extent aesthetically flawed. However, the condition this revision introduces is seductive work-specific, not independently motivated, and thus ad hoc, even supposing it preserves MP.

\subsection{Ontological proposal}

The discussion so far assumes seductive works prescribe two orders of

16 A similar problem arises for seductive works executing a gradual shift from one standard to another.

17 Gaut recognizes the possibility of synchronic seductive works in his discussion of Lolita [2007: 197]. 
response. The ontological proposal denies this. It proposes that the 'firstorder response' is actually part of the seductive work itself; seductive works only prescribe the 'second-order' response (in inverted commas because the proposal makes these first-order responses).

I believe the only way this proposal could work is by understanding seductive works as interactive artworks. It is natural to think interactive works include appreciators or their attitudes. The installation 21 Balancoires, for instance, was a temporary swing-set that played musical notes. The piece encouraged participants to co-operate by swinging in tandem, since this alone combined the sounds harmoniously [Andraos and Mongiat: 2012]. Participants might seem part of interactive works, rather than mere appreciators, not least because they form part of what others not directly interacting with such works are meant to appreciate. Similarly, one might think that in responding as prescribed to their own attitudes, appreciators of what I have been calling the 'work', or their 'first-order' attitudes, become part of a larger meta-work. Thus, while containing the unmerited responses, seductive works only prescribe the merited 'second-order' responses. To illustrate, the proposal is that the work Man Bites Dog consists not merely of a film, but of a film plus the appreciator's 'first-order' amusement. The only relevant response Man Bites Dog prescribes, therefore, is that of merited shame towards that amusement, leaving the work unblemished from MP's perspective.

If acceptable as an account of interactive works, this proposal promises an escape from paradox for at least some seductive works. Brett Bailey's Exbibit B, for instance, is an installation artwork depicting a fictional 'human zoo' populated by actors racialized as Black [2014]. ${ }^{18}$ On one plausible interpretation, the work prescribes a racialized objectifying gaze in order to make appreciators recognize their susceptibility to such a gaze, in particular, by meeting eyes with the otherwise objectified actors. Exhibit B's power lies not merely in making a spectacle of the actors, but of the appreciators as they execute their immoral gazes. As with 21 Balancoires, participants might be thought part of the artwork itself.

Characterizing interactive works as including appreciators is common but not inevitable. At least as plausibly, they do not include appreciators or their attitudes, even if the interactions they enable do. ${ }^{19}$ That aside, even granting interactive works contain appreciators or their attitudes, and even if Exbibit $B$ is among such works, it is doubtful that works like

18 I thank Nathaniel Coleman and James McGuiggan for the example.

19 The nascent ontology of interactive artworks offers just a few well-developed accounts: (roughly) that such works must give perceptible output to appreciator input [Saltz 1997], are types tokened by their interactions [Lopes 2001], are sets of display types (ways with which the work can be interacted) [Preston 2014], or are works whose aesthetic structure is intended to be alterable by appreciators aware of this intended alterability [Frome 2009]. Notably, David Saltz alone appears to accommodate appreciators or their attitudes as partly constituting performances comprising some interactive artworks, though Dominic McIver Lopes convincingly argues this is mistaken [2001: 79]. 
Man Bites Dog are. If nothing else, participants cannot substantively alter these works' contents or the appreciations they enable as with interactive works. At best, Exhibit B shows only that some seductive works are interactive, not all.

Putting aside the interactivity issue, the proposal suffers by appealing to something too common among artworks to justify it. Its motivating thought is that seductive works are fundamentally about, and prescribe responses to, the appreciator's attitudes, and that they therefore literally contain them. However, works fundamentally about, and prescribing responses to, things outside the work (including appreciators' attitudes) abound. Any work contemplating the human condition does this without thereby incorporating appreciators or their attitudes in the metaphysical sense the proposal requires-unless one embraces a radically new ontology of art.

\subsection{Complex responses proposal}

Perhaps claiming that seductive works prescribe unmerited first-order responses assumes too microscopic a view; the only aesthetically relevant response a seductive work prescribes is to the work as a whole-consisting in, say, 'understanding one's follies'. Since successful seductive works prescribe a merited response to the work as a whole, in any relevant sense they prescribe no unmerited response.

One minor problem with the proposal is that some seductions do not span entire works. Early in the film La Cage aux Folles, for instance, a SaintTropez club's middle-aged, homosexual proprietor, Renato sends his star attraction and partner onto stage, returns to their apartment, and prepares for a guest. He has a maid lay out champagne, tidies a bouquet of roses, applies powder, and dims the lights. When dashing young Laurent rings the bell, Renato checks his reflection, opens the door, and embraces him. Renato tells Laurent he is handsomer than ever, plays with his hair, kisses his forehead, and assures him they will not be disturbed. Appreciators are to believe that Renato has lured this boy to his apartment in his partner's absence. However, one quickly learns that Laurent is not Renato's lover but his son; the apparent erotic intimations were innocent displays of paternal affection [Molinaro 1978]. The film cleverly exploits stereotypes, especially widespread when released, of (male) homosexuals as promiscuous and paedophilic, thereby prescribing appreciators to think Renato a sexual predator. Upon accentuating Renato's innocence, it prescribes shame at their hasty judgment. ${ }^{20}$ Importantly, the seduction spans just one scene, frustrating the current proposal.

One could restrict MP to responses to an artwork's seductive parts, up to and including whole works. But a deeper problem awaits: why restrict at all? In other cases, finer- and coarser-grained prescriptions help

20 Thanks to Jamie Tappenden for this example. 
determine the work's aesthetic value. Thrillers, for instance, succeed on the whole by being exciting. But if they feature some mediocre actionprescriptions of unmerited excitement-this normally diminishes them. There are no grounds for treating seductive works differently, except to avert paradox. Unsupplemented, this is ad hoc.

One might argue that this proposal takes a finer-not a coarser-grained view by acknowledging that seductive works prescribe an internally complex, temporally structured (henceforth 'complex') response that can be merited. The proposal is therefore not ad hoc, since it honours the spirit of MP that Moran's earlier quote captures: works not achieving what they strive to are thereby worse. Since seductive works strive to secure their characteristic complex response, they should be judged on meriting that response, which successful seductive works do, and not on meriting the sub-responses comprising it.

But does MP's alleged spirit really justify focusing exclusively on complex responses? While seductive works strive to secure a complex response, securing the first- and second-order 'sub-responses' is a necessary means to that goal. So if MP's motivation is that works failing to do what they strive to are thereby worse, and seductive works must strive to secure first- and second-order responses in order to secure the complex one, then failing to merit these responses is failing to do what they strive to do. By the spirit or the letter, MP still leads to paradox.

\subsection{Seeming proposal}

A final proposal against (2) is that seductive works need not prescribe the unmerited first-order response, only seem to. Gaut takes this position. $\mathrm{He}$ wants to deny that seductive works are ethically flawed for prescribing unethical first-order responses. So he denies they prescribe the first-order responses at all. Man Bites Dog, for instance, merely appears to prescribe amusement, fooling careless appreciators [2007: 192].

As discussed in $\$ 1$, Gaut's notion of prescription is not a success concept, unlike Walton's. Indeed, it cannot be, otherwise MP would be pointless. This difference helps explain the current proposal's difficulty. In one respect artworks must meet a high bar to count as prescribing a response in Walton's sense-they must merit it-while prescribing a response in Gaut's sense requires only attempting to elicit it. Yet, the current proposal denies seductive works meet this low bar. ${ }^{21}$

How might a seductive work merely seem to prescribe the unmerited response it structurally needs? One way is by eliciting the response without prescribing it. I may inadvertently frighten someone by sneezing, without prescribing that they feel fear. Artworks, similarly, can elicit responses without attempting to elicit them, as when Michelangelo's David

21 Compare Lee Walters's more successful defence of an analogous solution (first formulated in [Walton 2015]) to a problem afflicting Waltonian prescription [2017]. 
reminds a viewer that she forgot to buy nuts. If seductive works do not prescribe unmerited first-order responses, do they prompt them in this way?

The problem with such promptings is that they are too chancy for successful seductive works. A seductive work that banks on eliciting a response as David reminds viewers of forgotten nuts would be structurally so capricious as to be absurd. The eliciting must be deliberate. So seductive works must at least attempt to give the impression- to make it seem-as though they prescribe the first-order response. But this amounts to prescribing that impression. Since this impression is false, this amounts to prescribing an unmerited response. So seductive works will still need to prescribe an unmerited response in order to merely seem to prescribe another.

One might retort that attempting to make it seem that $r$ is prescribed does not require prescribing the impression that $r$ is prescribed. Compare a general who wants both an illegal invasion and plausible deniability, and so tries to make it seem to her troops that she has ordered the invasion without actually ordering it. In so trying, she does not need to order her troops to believe she ordered the invasion. Similarly, one need not prescribe an impression to give it.

However, the cases differ. Militarily ordering $\varphi$ requires more than attempting to provoke $\varphi$. And, putting aside such an order's absurdity, ordering troops to have some impression requires more than attempting to give them that impression. The general must sign relevant paperwork or utter appropriate words in the right context. But, since on Gaut's 'prescribe' attempting to make appreciators have response $r$ just is to prescribe $r$, to say a work attempts to give an impression just is to say the work prescribes that impression.

I prefer saying seductive works prescribe their first-order responses to saying they prescribe the impression of this. Not only is this simpler, it also captures how the work strives to make it normative for appreciators to respond in an unmerited way. But I have shown that if the other analysis is preferred, it fares no better than battling a hangover with gin, merely reproducing the problem it is meant to cure. ${ }^{22}$

22 One can read Gaut as treating 'prescription' as a concept with two necessary conditions: to prescribe a response is to attempt to elicit it and to endorse it (i.e. as appropriate to comparable things in the actual world). This would explain his claim that seductive works do not prescribe the first-order response (since clearly they do not endorse it - that is the point). However, I do not think this proposed concept works for Gaut, though explaining why is tricky, requiring its own paper. One quick reason: while it is easy to understand how Aesop's The Ant and the Grasshopper endorses hard work, it makes little sense to think it endorses the claim that an ant spoke to a grasshopper; however, it certainly prescribes both claims. 


\section{Rejecting (3)}

If (2) stands, the remaining option to salvage MP is rejecting (3), by accepting that seductive works are necessarily aesthetically flawed. ${ }^{23}$

\subsection{Minor flaws proposal}

Seductive works, one might say, prescribe unmerited responses, but this blemish is dwarfed by the great achievement it enables: indicting the appreciators' attitudes.

However, this turns achievement into failure. Successful seductive works are estimable not merely for subverting our complacent responses, ${ }^{24}$ but also for doing so by skilfully obscuring matters just enough to elicit an unmerited response without undermining the secondorder one. Threading that needle ought to count as an aesthetic merit, not a blemish.

Perhaps the thought is that if seductive works could grant their insights without the dishonour of prescribing unmerited responses, they would be aesthetically better. ${ }^{25}$ But this presupposes that a seductive work's distinctive value is the insight it reveals and that it is in principle separable from the first-order response it prescribes. This is an important value in seductive works. But more important, I suggest, is how seductive works reveal this. Besides the skill achieving this revelation exhibits, the value lies in the distinctive experience of self-examination seductive works afford appreciators, which no other approach can. The unmerited response is not merely necessary for achieving this distinctive experience-in part it is this experience.

\subsection{Epistemic privilege proposal}

Still, while making appreciators respond in unmerited ways can be an achievement, perhaps letting this fully absolve seductive works fails to take seriously how this tactic compromises the work. For instance, an appreciator who has suffered from the kinds of crimes at which Man Bites Dog prescribes amusement might be unable to appreciate the film at all, finding these prescriptions irredeemably tasteless. One could discount this appreciator's judgment as hypersensitive. But one could also conclude that her experience grants an epistemic privilege concerning representations of violent crime; those without this experience are glib to deny that trivializing such acts blemishes the work. ${ }^{26}$

23 Katherine Thomson-Jones [2012: 286] appears to describe this position.

24 Lucy O'Brien describes offering complacent readers soothing 'truths' before casting doubt upon them as among 'the most important things novels can do' [2017: 140], a claim with obvious applications beyond novels.

25 This is almost right, as I discuss in $\$ 7$.

26 Thanks to Victor Kumar for pressing this objection. 
I am sympathetic, though more argument is needed. It is doubtful that seductive works always trivialize the objects of the first-order responses they prescribe. Another issue is how far the claim goes. If a depiction of domestic violence does not amuse a domestic violence victim, denying that it is amusing may be plausible. But where someone's father, say, dies after taking a pie to the face, it is less plausible to think she enjoys some epistemic privilege concerning which pie-gag responses are appropriate. Another complication is locating where epistemic privilege lies. Perhaps in general, privilege lies with the represented offense's victims, although this position raises awkward questions about victimhood. To take one example, NWA's Fuck the Police is both an expression of indignation at state oppression and a call to arms against the police [1988]. Who should one privilege concerning such a work? The oppressed? Victims of antipolice violence? Both? (Note: I am not suggesting moral equivalence). In any case, accepting the suggestion only immunizes certain works against paradox. Some seductive works such as Exbibit B or Man Bites Dog might be aesthetically flawed for the ethical reasons just described, but not all. Seductive works prescribing responses unmerited to only a minor ethical degree, or for non-ethical reasons, such as the Boddington's advertisement, do not plausibly fall within this category.

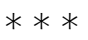

I contend that none of the solutions considered works, though my interest is as much in charting the possible routes out of the paradox as in closing them off. However, since those routes do look closed, I propose rejecting MP. Aristotle claimed that successful tragedies exploit the ordinary person's unmerited misfortunes. It appears successful seductive works exploit her unmerited responses.

\section{The challenge of seductive works}

What seductive works reveal, I argue, is that one cannot determine an artwork's prescriptions' success using an unvarnished notion of meritedness, as MP does. Intuitively, what motivates MP is the observation that works failing to move their audiences as intended fail on their own terms. ${ }^{27}$ But note this claim is couched in EP's causal register, not MP's normative one. Seductive works, like others, are made for actual audiences whose susceptibilities to be misled are known. When a seductive work secures both the first-order response and the secondorder repudiation, it is to that extent successful. Appealing to meritedness without qualification obscures this part of a seductive work's achievement.

27 Prescribed responses need not exhaust a work's 'own terms'. Some works may simply explore a subject, letting audiences respond as they will. 
Putting this in terms of an ideal appreciator may clarify the problem. Suppose a response $r$ to $x$ is merited if and only if an ideal appreciator has response $r$ to $x$. Then MP's problem is this: for seductive works to succeed, appreciators must get things wrong. But ideal appreciators always get things right. Therefore, just as aesthetic success cannot be measured (straightforwardly) by ideal appreciator responses, nor can it be (straightforwardly) measured by whether a work's prescribed responses are merited.

One might try to save the meritedness-only approach by relaxing the standards of seductive works somewhat. Capturing this relaxed normativity in terms of the appreciator, the idea would be to relax idealization so that ideal appreciators can get things wrong, in some sense, yet remain authoritative- to be 'sufficiently ideal'. Hume's ur-account of ideal aesthetic appreciators appears to do this when he qualifies his requirement that ideal appreciators eschew all prejudice with the condition that, since an artist 'addresses himself to a particular audience' with 'regard to their particular genius, interests, opinions, passions, and prejudices', he must also 'place himself in the same situation as the audience, in order to form a true judgment' [1757b: 224-5].

However, at whichever level one pitches the idealization, the problem remains. This is because-and this is the heart of why seductive works are theoretically so fascinating-seductive works must make sufficiently ideal appreciators see how their first-order response was unmerited by their own sufficiently ideal standards. Wherever one pitches the standard, provided it remains the same throughout the work, a gap must remain between the first-order response the work prescribes and the one it merits. Without such a gap, the work fails, since the second-order response it prescribes will be unmerited. Putting it differently, no level of idealization will reconcile MP to seductive works because what such works reveal is how the appreciator fails to be sufficiently ideal.

This becomes clearer once one compares seductive works to their non-seductive cousins. Inferences, including about artworks, often proceed non-monotonically - that is, further evidence can defeat prior evidence, forcing a new conclusion. ${ }^{28} \mathrm{~A}$ standard murder mystery might convince us the butler did it before revealing the vicar did. Furthermore, appreciators often draw correct inferences about what is fictional from what would ordinarily be very flimsy evidence [Walton 1990: 161-8], making this kind of evidential shift easier still. Given this, one may insist that both inferences, first to the butler's guilt, later to the vicar's, are merited given the evidence available at the time. One might then insist that seductive works - at least diachronic ones-likewise rely on such an evidential shift, allowing both orders of response to be merited. This is analogous with the shifting standards proposal dismissed earlier, except that here the operative standard does not shift, the evidence does.

28 On fiction and non-monotonicity, see [Walters 2015]. 
However, seductive works do not execute an epistemic shift like such a misleading murder mystery; this is why murder mysteries are not typically seductive works. For a work to be truly seductive, it must give the appreciator just enough rope with which to hang herself rather than (to strain the metaphor) disguising the noose as a scarf. Seductive works are distinctive in showing appreciators how they, rather than the evidence the work gave them, falls short; ${ }^{29}$ their deficiency must bridge the gap between what the prescription merits and what it prescribes. Compare the standard murder mystery to one exploiting appreciators' racial prejudices to induce the belief that a butler conspicuously racialized as Black is guilty. To the extent that these prejudices prompt otherwise unmerited inferences, and the work exhibits all the other appropriate structural features, it counts as seductive. ${ }^{30}$

\section{Reforming MP}

What flaw does MP fail to quite capture then? EP comes close, but faces the familiar imperfect appreciators problem. A way to reform EP without resorting to MP's normative register is to restrict it to intended appreciators:

\section{ELICITATION PRINCIPLE* (EP*)}

A work that prescribes but fails to elicit a response in intended appreciators through artistic means is to that extent aesthetically flawed.

EP* retains EP's causal benefits, avoids its disadvantages, and diagnoses seductive works correctly. But it introduces a new problem: trivially flawless prescriptions. Some works prescribe asinine responses. If one characterizes intended appreciators as asinine, EP* deems these prescriptions aesthetically blameless. But it is no defence of, say, Independence Day [Emmerich 1996] to claim that it is meant for idiots. Of course, since EP* gives only a sufficient condition for failure, such cases are not strictly counterexamples. Rather, similarly to how $₫ 4.2$ 's proposal failed, they undermine EP*'s claim to capture the general flaw in prescribing defective responses-to match MP's explanatory ambition. Nonetheless, EP* points to a more promising alternative.

Comparing cases like Independence Day to works accommodating other deficiencies reveals another possibility. Children's literature is written for psychologically immature appreciators, yet not therefore defective as mindless blockbusters are. Culpability seems important. Children are generally blameless for their shortcomings as many obtuse adults are not;

29 Gaut [2007: 192] appears to endorse this point.

30 I take the examples I have considered to be seductive works understood this way. But provided the conceptual possibility of seductive works exists, the paradox arises_-even if, contingently, no seductive work existed. 
children's works accommodate shortcomings, while mindless blockbusters pander to them. The source of this distinction is, I propose, what determines whether some imperfections-better, limitations - constitute flaws, and explains why seductive works avoid blemish despite having a limitation. Specifically, I suggest, whether limitations mar a work aesthetically depends on whether (a) the constraints imposing the limitations are (aesthetically) worthwhile, and (b) whether any limitations are only as large as such constraints require. Combining these two conditions gives us:

\section{NEW MERIT PRINCIPLE}

A work that prescribes an unmerited response through artistic means is aesthetically flawed, unless the response is unmerited entirely because of aesthetically worthwhile constraints under which the work operates.

Regarding seductive works, if pursuing seduction is worthwhile, prescribing unmerited responses blemishes seductive works aesthetically only to the extent their lack of meritedness exceeds whatever seduction requires.

I have offered a new principle that appears to correctly evaluate seductive works while preserving MP's ambition. While I lack space to defend it comprehensively, I will end by briefly motivating it. The New Merit Principle draws upon a broader recognition that limitations, while recognized as such, do not necessarily blemish a work aesthetically. Constraints limit an artwork's capacity to exemplify certain aesthetic virtues. Photography executed with antiquated equipment, for instance, cannot exhibit many of Photoshopped digital photography's visual virtues. However, more constrained works are not thereby aesthetically flawed. In part, this is because some constraints are necessary for achieving other aesthetic values. The exquisitely fleshy softness Gian Lorenzo Bernini achieves in marble, for instance, would be underwhelming were it realized in soap. But, more generally, all works operate under constraints - being a painting rather than a film, or executed in ink, or Noh theatre, or chiptune, etc.-which is just to say every work, trivially, has limitations because no work could maximally possess every aesthetic virtue.

This fact explains the competing intuitions behind MP and proposition (3). Seductive works do not exhibit the constraintindependent virtue of meriting every prescribed response, and are in that respect sub-ideal; yet, successful seductive works prescribe responses that are as merited as possible, conditional on being seductive. So this diminished meritedness is no more a flaw than a cubist painting's diminished gracefulness, or a baiku's threadbare narrative is. Seductive works, like all artworks, faultlessly do not exhibit some constraint- 
independent virtues. ${ }^{31}$

Naturally, some constraint-induced limitations are flaws, because the constraints are not aesthetically worthwhile, as with mindless blockbusters or works executed in an inappropriate medium. What makes constraints worthwhile? I cannot give a full answer here, though suggest constraints posing interesting artistic problems to overcome, ${ }^{32}$ or enabling other sufficiently compensatory aesthetic virtues, are to that extent worthwhile; those that do not are not. And cases like Bernini's sculptures and Independence Day can anchor the distinction. Concerning seductive works, provided that pursuing seduction counts as worthwhile, this is all the argument needs. This is easy to motivate: with great skill, seductive works make one reflect on one's responses ${ }^{33}$ through a unique, rich, and edifying experience of one's own deficiency. ${ }^{34}$

\section{Conclusion}

I showed that the intuitive Merit Principle conflicts with what I call seductive artworks by entailing, oddly, that they are necessarily aesthetically flawed. I considered the most promising strategies for preserving the Merit Principle, showing how each fails. I then raised a general doubt about the prospects for any such strategy: because of the way successful seductive artworks rely on appreciator deficiency, deficiency is baked into what makes the artwork succeed, a fact the Merit Principle cannot accommodate. Finally, I briefly defended an alternative principle appealing to a general way artistic constraints condition aesthetic value: the New Merit Principle. ${ }^{35}$ While this brief defence surely raises new questions, the principle satisfactorily resolves the paradox and explains the competing intuitions behind it.

31 The artistic importance of constraints to aesthetic value, given and self-imposed, is widely acknowledged. See, for instance, [Nolan 1974], especially on pages 71-3, and [Davies 2004: 68-71]. On category constraints, see [Walton 1970].

32 Anne Eaton [2012] 'implicitly' conceives of artworks as solutions to more or less interesting problems. She cites Michael Baxandall [1983], who considers this fundamental to paintings. Denis Dutton [1979] considers problem-solving fundamental to the very concept of an artwork, especially on pages 305-7. Cynthia Freeland suggests one 'can think about art as a form of problem solving' in accounting for artistic progress [Freeland and Maes 2017: 108].

33 Jenefer Robinson claims the best novels (one can substitute 'artworks') are those inviting 'reflection about the emotions that they induce' [Robinson and Maes 2017: 163].

34 What does my proposal mean for Gaut's Merited Response Argument? Whether it works now hinges on whether constraints limiting ethical meritedness-such as being unethical, or being ethically seductive-are ever worthwhile. For related discussion, see [Sauchelli 2013].

35 I suggest MP's defenders rebrand it as Merit Principle Classic to regain market-share. 


\section{References}

Andraos, Mouna and Melissa Mongiat 2012. 21 Balançoires [installation artwork], Daily Tous Les Jours: Montreal.

Aristotle (1898). The Poetics of Aristotle, ed. S.H. Butcher, trans. S.H. Butcher, London: Macmillan.

Bailey, Brett 2014. Exbibit B, The Barbican: London.

Bartle Bogal Hegarty 1996. The Body, The Cream of Manchester [advertising campaign], London.

Baxandall, Michael 1985. Patterns of Intention: On the Historical Explanation of Pictures, London: Yale University Press.

Belvaux, Rémy, André Bonzel, and Benoît Poelvoorde 1992. Man Bites Dog [feature film], London: Metro Tartan Films

Brooker, Charlie 2011. The National Anthem, Black Mirror [television series]. London: Channel 4.

Carroll, Noël 1996. Moderate Moralism, The British Journal of Aesthetics 36/3: 223-38.

Carroll, Noël 2000. Art and Ethical Criticism: An Overview of Recent Directions of Research, Ethics 110/2: 350-87.

Clavel-Vázquez, Adriana forthcoming. Rethinking Autonomism: Beauty in a World of Moral Anarchy, Philosophy Compass.

Curran, Angela 1998. Feminism and the Narrative Structure of the Poetics, in Feminist Interpretations of Aristotle, ed. Cynthia A. Freeland, University Park, PA: The Pennsylvania University Press: 289-326.

Curran, Angela 2016. Aristotle and the Poetics, Oxford: Routledge.

Davies, David 2004. Art as Performance, Oxford: Blackwell.

Dutton, Denis 1979. Artistic Crimes: The Problem of Forgery in the Arts, The British Journal of Aesthetics 19/4: 302-14.

Eaton, A.W. 2012. Robust Immoralism, The Journal of Aesthetics and Art Criticism 70/3: 281-92.

Emmerich, Roland 1996. Independence Day [feature film], Los Angeles: 20th Century Fox.

Freeland, Cynthia A. 1992. Plot Imitates Action: Aesthetic Evaluation and Moral Realism in Aristotle's Poetics, in Essays on Aristotle's Poetics, ed. Amélie Oksenberg Rorty, Princeton: Princeton University Press: $111-32$.

Freeland, Cynthia A. and Hans Maes 2017. Inside Out: Portraits, Art, Science. A Conversation with Cynthia Freeland, in Conversations on Art and Aesthetics, ed. Hans Maes, Oxford: Oxford University Press: 83- 
111.

Frome, Jonathan 2009. The Ontology of Interactivity, Proceedings of the Philosophy of Computer Games Conference, Oslo: University of Oslo.

Gaut, Berys 1998. The Ethical Criticism of Art., in Aesthetics and Ethics: Essays at the Intersection, ed. Jerrold Levinson, Cambridge: Cambridge University Press: 182-203.

Gaut, Berys 2007. Art, Emotion and Ethics, Oxford: Oxford University Press.

Gaut, Berys 2010. A Philosophy of Cinematic Art, Cambridge: Cambridge University Press.

Harold, James 2008. Immoralism and the Valence Constraint, The British Journal of Aesthetics 48/1: 45-64.

Hume, David 1757a. Of Tragedy, in Four Dissertations, David Hume. London: A. Millar: 185-200.

Hume, David 1757b. Of the Standard of Taste, in Four Dissertations, David Hume. London: A. Millar: 203-40

Jacobson, Daniel 1997. In Praise of Immoral Art, Philosophical Topics 25/1: 155-99.

Jacobson, Daniel 2008. Review of Berys Gaut - Art, Emotion and Ethics. Notre Dame Philosophical Reviews, URL = $<$ https://ndpr.nd.edu/news/art-emotion-and-ethics/>.

John, Eileen 2009. Review of Berys Gaut - Art, Emotion and Ethics, The British Journal of Aesthetics 49/2: 185-8.

Kieran, Matthew 2006. Art, Morality and Ethics: On the (Im)Moral Character of Art Works and Inter-relations to Artistic Value, Philosophy Compass 1/2: 129-43.

McIver Lopes, Dominic 2001. The Ontology of Interactive Art, The Journal of Aesthetic Education 35/4: 65-81.

Molinaro, Édouard 1978. La Cage aux Folles [feature film], Beverly Hills: United Artists.

Moran, Richard 1994. The Expression of Feeling in Imagination, The Philosophical Review 103/1: 75-106.

Nolan, Rita 1974. The Character of Writings by Artists about Their Art, The Journal of Aesthetics and Art Criticism 33/1: 67-73.

N.W.A. 1988. Fuck the Police, Straight Outta Compton [audio recording], Los Angeles: Ruthless Records.

O'Brien, Lucy 2017. The Novel as a Source of Self-Knowledge, in Art and Belief, eds. Ema Sullivan-Bissett, Helen Bradley, and Paul 
Noordhof, Oxford: Oxford University Press: 135-50.

Parfit, Derek 2011. On What Matters, Vol. 1, Oxford: Oxford University Press.

Petersen, Wolfgang 1981. Das Boot [feature film], Munich: Constantin Film AG.

Picasso, Pablo 1937. Guernica [painting], Madrid: Museo Nacional Centro de Arte Reina Sofía.

Pliny the Elder (1857). The Natural History, trans. John Bostock and H.T. Riley, London: Henry G. Bohn.

Preston, Dominic 2014. Some Ontology of Interactive Art, Philosophy and Technology 27/2: 267-78.

Robinson, Jenefer and Hans Maes 2017. The Emotions in Art. A Conversation with Jenefer Robinson, in Conversations on Art and Aesthetics, ed. Hans Maes, Oxford: Oxford University Press: 145-77.

Saltz, David Z. 1997. The Art of Interaction: Interactivity, Performativity, and Computers, The Journal of Aesthetics and Art Criticism 55/2: 11727.

Sauchelli, Andrea 2013. The Merited Response Argument and Artistic Categories, The Journal of Aesthetics and Art Criticism 71/3: 239-46.

Smuts, Aaron. 2007. The Joke is the Thing: In the Company of Men and the Ethics of Humor, Film and Philosophy 11/1: 49-65.

Smuts, Aaron 2011. Rubber Ring - Why Do We Listen to Sad Songs?, in Narrative, Emotion, and Insight, ed. Noël Carroll and John Gibson, University Park, PA: Penn State Press: 131-53.

Stear, Nils-Hennes 2015. Imaginative and Fictionality Failure: A Normative Approach, Philosophers' Imprint 15/34: 1-18.

Stecker, Robert 2005. The Interaction of Ethical and Aesthetic Value, The British Journal of Aesthetics 45/2: 138-50.

Taylor, Paul C. 2016. Black is Beautiful: A Philosophy of Black Aesthetics, Chichester: John Wiley \& Sons.

Thomson-Jones, Katherine 2012. Art, Ethics, and Critical Pluralism, Metaphilosopby 43/3: 275-93.

Walters, Lee 2015. Serial Fiction, the End? The British Journal of Aesthetics 55/3: 323-41.

Walters, Lee 2017. Fictionality and Imagination, Revisited, The Journal of Aesthetics and Art Criticism 75/1: 15-21.

Walton, Kendall L. 1970. Categories of Art, The Philosophical Review 79/3: 334-67. 
Walton, Kendall L. 1990. Mimesis as Make-Believe: On the Foundations of the Representational Arts, Cambridge, MA: Harvard University Press.

Walton, Kendall L. 2015. Fictionality and Imagination - Mind the Gap, in In Other Shoes: Music, Metaphor, Empathy, Existence, Kendall L. Walton, Oxford: Oxford University Press: 17-35. 